\title{
The Structures of Fluostatins C, D and E, Novel Members of the Fluostatin Family
}

\author{
Kathrin Schneider, Graeme Nicholson, Markus Ströbele, Stephanie Baur, Jörg Niehaus, \\ Hans-Peter Fiedler, Roderich D. Süssmuth
}

Received: October 27, 2005 / Accepted: February 3, 2006

(C) Japan Antibiotics Research Association

\begin{abstract}
Three new fluostatin antibiotics have been isolated from the culture filtrate of Streptomyces strain Acta 1383. The chemical structures of these compounds were determined by mass spectrometry and NMR spectroscopy. The relative configuration has been determined by X-ray crystal structure analysis and the absolute configuration was deduced from NMR data with the help of Helmchen esters. These compounds represent the first reported epoxide fluostatins $(\mathbf{1}, \mathbf{2})$ and underline previously found analogies to the group of kinamycin antibiotics.
\end{abstract}

Keywords fluostatin, kinamycin, structure elucidation

\section{Introduction}

Our HPLC screening program revealed three novel, structurally related compounds $(\mathbf{1}, \mathbf{2}, \mathbf{3})$, isolated from the culture broth of Streptomyces strain Acta 1383. Compound 1 showed a moderate inhibition of the proliferation of human cell lines from gastric adenocarcinoma, breast carcinoma and hepatocellular carcinoma. The taxonomy of the producing strain, fermentation, isolation and biological activities are reported in a preceding paper [1]. In order to characterize the chemical structure mass spectrometry, NMR spectroscopy and X-ray crystallographic analysis were performed.

\section{Results}

Screening of culture extracts was performed by HPLCDAD and HPLC-ESI-MS. The secondary metabolites profile of Streptomyces strain Acta 1383 obtained by HPLC-DAD analysis for $\mathbf{1}, \mathbf{2}$ and $\mathbf{3}$ could not be assigned to any known metabolites by means of our HPLC-UVVis Database [2]. The HPLC-ESI-MS spectra revealed molecular masses for $\mathbf{1}\left[(\mathrm{M}+\mathrm{H})^{+}=325.4\right], \mathbf{2}\left[(\mathrm{M}+\mathrm{Na})^{+}=\right.$ 417.2] and $3\left[(\mathrm{M}+\mathrm{Na})^{+}=383.0\right]$. The characteristic isotopic pattern of $\mathbf{3}$ indicated the presence of chlorine. This assumption was confirmed by the molecular formulae obtained by means of high resolution ESI-FT-ICRMS measurements. The exact masses determined for 1, 2 and 3 were $323.05650 \mathrm{Da}\left[(\mathrm{M}-\mathrm{H})^{-}\right], 395.11288 \mathrm{Da}$ $\left[(\mathrm{M}+\mathrm{H})^{+}\right]$and $383.03021 \mathrm{Da}\left[(\mathrm{M}+\mathrm{Na})^{+}\right]$, corresponding to the molecular formulae $\mathrm{C}_{18} \mathrm{H}_{12} \mathrm{O}_{6}(\mathbf{1})\left[(\mathrm{M}-\mathrm{H})_{\text {theor }}^{-}=\right.$ $323.05611 ; \Delta \mathrm{m}=1.2 \mathrm{ppm}], \mathrm{C}_{22} \mathrm{H}_{18} \mathrm{O}_{7}$ (2) $\left[(\mathrm{M}+\mathrm{H})_{\text {theor }}^{+}=\right.$ 395.11252; $\Delta \mathrm{m}=0.9 \mathrm{ppm}]$ and $\mathrm{C}_{18} \mathrm{H}_{13} \mathrm{O}_{6} \mathrm{Cl}$ (3) $[(\mathrm{M}+$ $\left.\mathrm{Na})_{\text {theor }}^{+}=383.02929 ; \Delta \mathrm{m}=2.4 \mathrm{ppm}\right]$.

The high carbon: hydrogen ratio combined with UV data suggested a predominantly aromatic character of the isolated compounds. The ${ }^{1} \mathrm{H}-\mathrm{NMR}$-spectra of $\mathbf{1}$ showed four signals in the aromatic and three signals in the aliphatic regions of the spectrum. Comparison of the ${ }^{13} \mathrm{C}$ spectra with the DEPT-spectra indicated one $\mathrm{CH}_{3}$-group
R. D. Süssmuth (Corresponding author), K. Schneider: Institut für Organische Chemie, Technische Universität Berlin, Straße des 17. Juni 124, D-10623 Berlin, Germany,

E-mail: suessmuth@chem.tu-berlin.de

G. Nicholson: Institut für Organische Chemie, Universität Tübingen, D-72076 Tübingen, Germany
M. Ströbele: Institut für Anorganische Chemie, Universität Tübingen, D-72076 Tübingen, Germany

H.-P. Fiedler, J. Niehaus, S. Baur: Mikrobiologisches Institut, Universität Tübingen, D-72076 Tübingen, Germany 
Table $1{ }^{1} \mathrm{H}$ and ${ }^{13} \mathrm{C}$ NMR data of fluostatins $\mathrm{C}(\mathbf{1}), \mathrm{D}(\mathbf{2})$ and $\mathrm{E}(\mathbf{3})$

\begin{tabular}{|c|c|c|c|c|c|c|}
\hline \multirow[b]{2}{*}{ No. } & \multicolumn{2}{|c|}{1 in DMSO- $d_{6}$} & \multicolumn{2}{|l|}{2 in $\mathrm{CD}_{3} \mathrm{OD}$} & \multicolumn{2}{|c|}{3 in DMSO- $d_{6}$} \\
\hline & $\delta\left({ }^{1} \mathrm{H}\right)[p p m] J$ in $\mathrm{Hz}$ & $\begin{array}{l}\delta\left({ }^{13} \mathrm{C}\right) \\
{[\mathrm{ppm}]}\end{array}$ & $\delta\left({ }^{1} \mathrm{H}\right)[\mathrm{ppm}] \mathrm{J}$ in $\mathrm{Hz}$ & $\begin{array}{l}\delta\left({ }^{13} \mathrm{C}\right) \\
{[\mathrm{ppm}]}\end{array}$ & $\delta\left({ }^{1} \mathrm{H}\right)[p p m] J$ in $\mathrm{Hz}$ & $\begin{array}{l}\delta\left({ }^{13} \mathrm{C}\right) \\
{[\mathrm{ppm}]}\end{array}$ \\
\hline 1 & 5.79 & 59.2 & 6.87 & 64.3 & 5.30 & 65.6 \\
\hline 2 & $3.78\left(\mathrm{~d}, J_{21}=8.51\right)$ & 62.2 & 3.89 & 61.1 & 4.11 & 75.9 \\
\hline 3 & - & 57.8 & - & 60.1 & - & 66.0 \\
\hline 4 & - & 193.6 & - & 194.4 & - & 190.8 \\
\hline $4 a$ & - & 130.7 & - & n.d. & - & 130.7 \\
\hline 5 & $7.12(\mathrm{~s})$ & 121.0 & $7.48(\mathrm{~s})$ & 122.0 & $7.53(\mathrm{~s})$ & 120.7 \\
\hline 6 & - & 155.4 & - & 154.0 & - & 150.1 \\
\hline $6 a$ & - & 137.1 & - & 137.1 & - & 135.6 \\
\hline $6 b$ & - & 127.7 & - & 128.0 & - & 125.5 \\
\hline 7 & - & 155.6 & - & 153.4 & - & 151.2 \\
\hline 8 & $6.79\left(\mathrm{~d}, J_{8,9}=8.05\right)$ & 124.7 & $7.00\left(d, J_{8,9}=7.96\right)$ & 124.9 & $7.08\left(\mathrm{~d}, J_{8,9}=8.39\right)$ & 124.0 \\
\hline 9 & $\begin{array}{c}7.07\left(\mathrm{dd}, J_{9,10}=7.00\right. \\
\left.J_{9,8}=8.05\right)\end{array}$ & 130.7 & $\begin{array}{c}7.22\left(\mathrm{dd}, J_{9,10}=7.20\right. \\
\left.J_{9,8}=7.96\right)\end{array}$ & 132.4 & $\begin{array}{c}7.31\left(\mathrm{dd}, J_{9,10}=7.26\right. \\
\left.J_{9,8}=8.39\right)\end{array}$ & 131.8 \\
\hline 10 & $6.88\left(d, J_{10,9}=7.00\right)$ & 113.2 & $7.15\left(d, J_{10,9}=7.20\right)$ & 117.2 & $7.20\left(d, J_{10,9}=7.26\right)$ & 116.1 \\
\hline $10 a$ & - & 134.8 & - & 137.3 & - & 135.2 \\
\hline 11 & - & 193.7 & - & 194.4 & - & 192.4 \\
\hline $11 a$ & - & 130.7 & - & 134.2 & - & 133.6 \\
\hline $11 b$ & - & 129.7 & - & 127.7 & - & 133.7 \\
\hline 12 & $1.49(\mathrm{~s})$ & 15.1 & $1.56(\mathrm{~s})$ & 15.1 & $1.68(\mathrm{~s})$ & 23.1 \\
\hline 13 & & & & 178.4 & & \\
\hline 14 & & & $2.54(\mathrm{~m})$ & 35.1 & & \\
\hline 15 & & & $1.10\left(d, J_{14,15}=7.00\right)$ & 19.3 & & \\
\hline 16 & & & $1.14\left(\mathrm{~d}, J_{14,16}=7.00\right)$ & 19.0 & & \\
\hline
\end{tabular}

and six $\mathrm{CH}$ fragments. Another three protons were assigned as attached to heteroatoms (aliphatic hydroxyl and phenols). The correlation of ${ }^{1} \mathrm{H}-\mathrm{NMR}$-signals to the corresponding C-atoms was carried out by the Heteronuclear Single Quantum Coherence (HSQC) NMR spectrum.

With the help of 2D NMR experiments the core structure of $\mathbf{1}, \mathbf{2}$ and $\mathbf{3}$ was determined to be a fluorenone bearing two phenolic hydroxyl groups. Two positions are available for the attachment of an additional aliphatic ring. The attachment site was determined from the Heteronuclear Multiple Bond Correlation (HMBC) experiment (Fig. 2). Two $J$-couplings, one from the aromatic proton $\mathrm{H}-5$ to the carbonyl carbon $\mathrm{C}-4$ and the other from the aliphatic proton $\mathrm{H}-1$ to the aromatic carbon $\mathrm{C}-11$ a suggested an attachment via $\mathrm{C}-11 \mathrm{~b}$ and $\mathrm{C}-4 \mathrm{a}$ of the fluorenone (Fig. 2). The DEPT spectrum revealed a carbonyl, a $\mathrm{CH}_{3}$, two $\mathrm{CH}$ groups and a quaternary $\mathrm{C}$-atom for the abovementioned aliphatic ring with the molecular formula of $\mathrm{C}_{5} \mathrm{H}_{6} \mathrm{O}_{3} \cdot{ }^{13} \mathrm{C}$-chemical shifts of C-2 and C-3 (62.2 and $57.8 \mathrm{ppm}$ ) in combination with 2D spectral data clearly indicated the presence of an epoxide in compound $\mathbf{1}$.

In parallel to NMR studies, crystallisation experiments were performed and for compound $\mathbf{1}$ a single crystal was obtained. Subsequent X-ray structure determination fully confirmed the constitutional formula as well as the relative configuration (Fig. 3) derived from the interpretation of the NMR data.

The ESI-FT-ICR-MS data of compounds $\mathbf{1}$ and $\mathbf{2}$ suggested that 2 contains an additional $\mathrm{C}_{4} \mathrm{H}_{6} \mathrm{O}$ fragment, for which the corresponding signals from two $\mathrm{CH}_{3}$ groups and one $\mathrm{CH}$ group in the ${ }^{1} \mathrm{H}$-spectrum were found. In the ${ }^{13} \mathrm{C}$-spectra a significant signal was obtained at $177.9 \mathrm{ppm}$ (C-13), characteristic for a carbonyl of an ester function. With the help of the 2D NMR experiments compound 2 was identified as the corresponding isobutyric ester of compound 1. The $J$-coupling observed in the HMBC experiment (Fig. 2) between $\mathrm{H}-1$ to $\mathrm{C}-13$ provided evidence for the attachment site of the ester at $\mathrm{C}-1$ of the fluostatin structure.

The formal difference of $\mathrm{HCl}$ between molecular 
<smiles>C[C@]12O[C@H]1[C@@H](O)c1c(cc(O)c3c1C(=O)c1cccc(O)c1-3)C2=O</smiles>

1<smiles>Cc1cc(=O)c2c(cc(O)c3c4c(O)cccc4c(=O)c32)c1=O</smiles>

4<smiles>CC(C)C(=O)O[C@H]1c2c(cc(O)c3c2C(=O)c2cccc(O)c2-3)C(=O)[C@@]2(C)O[C@H]12</smiles><smiles>CC1C(=O)c2cc(O)c3c(c2C(O)C1O)C(=O)c1cccc(O)c1C3</smiles>

5<smiles>C[C@]1(Cl)C(=O)c2cc(O)c3c(c2C(=O)[C@H]1O)C(=O)c1cccc(O)c1-3</smiles>

3<smiles>C[C@]12O[C@H]1[C@@H](O)C1=C(C2=O)C2=C(C(=O)c3cccc(O)c3C2=O)C1[NH3+]</smiles>

6

Fig. 1 Structures of fluostatins C (1), D (2), E (3), A (4), B (5), and ketoanhydrokinamycin (6).
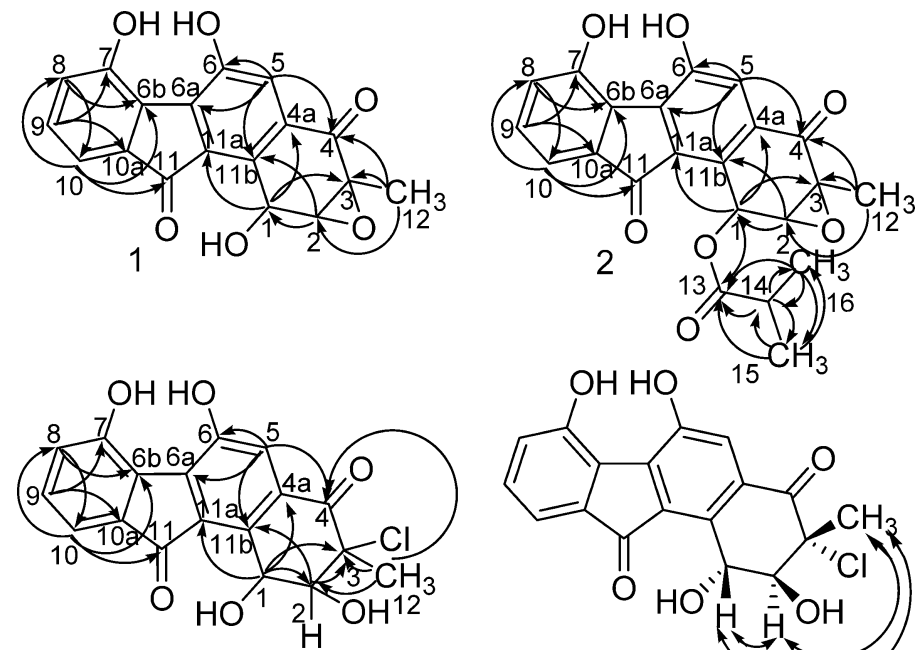

$3 a$

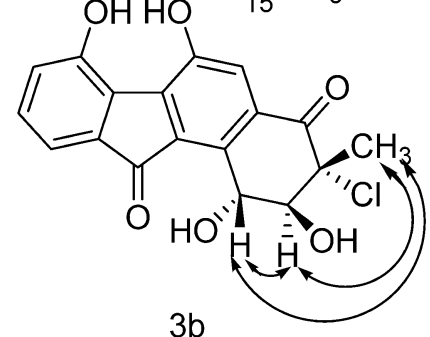

Fig. 2 HMBC correlations for C (1), D (2), E (3a) and sel. NOE correlations for E (3b).

formulae of $\mathbf{1}$ and $\mathbf{3}$, supported by interpretation of 2DNMR data sets, identified 3 as resulting from ring opening of the epoxide (C-2 and C-3). The evaluation of the NMR data provided the structure shown in Fig. 1.

Finally, experiments were performed in order to assign the absolute stereochemistry in compound $\mathbf{1}$ using the Helmchen method applied to phenylbutyric acid esters 7 and 8 [3]. The application of this method suggested an $(R)-$ configuration at $\mathrm{C}-1$. Based on the configuration at $\mathrm{C}-1$ combined with the data on relative configuration from $\mathrm{X}$ ray structures the absolute stereochemistry of $\mathbf{1}$ was deduced as shown in Fig. 1. On the basis of structural analogy, the same configurations were assumed for the

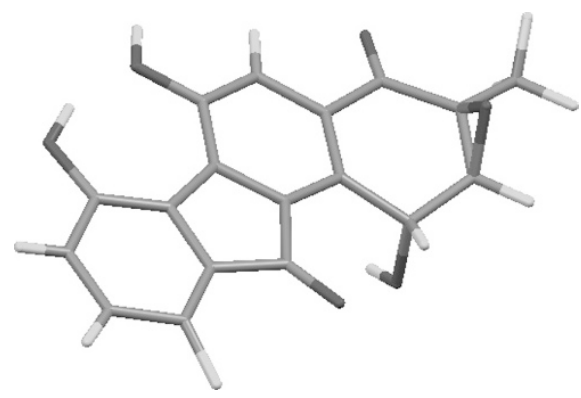

Fig. 3 X-Ray structure of fluostatin C. 
analogous positions in compounds 2 and the positions 1 and 2 in compound $\mathbf{3}$. The relative stereochemistry at C-3 was deduced from selective NOE experiments. The results of these experiments are shown in Fig. 2.

\section{Discussion}

The chemical structures of $\mathbf{1}, \mathbf{2}$ and $\mathbf{3}$ reveal a strong relationship to fluostatins A (4) and B (5) [4] and therefore these compounds were assigned within the fluostatin family. To date only two compounds of this family have been described, which lack configurational assignment of chiral centres. Interestingly, $\mathbf{1}$ is the corresponding epoxy analogue of fluostatin B. The positions of the ketone, methyl and hydroxyl groups were found to be identical to fluostatin B. Derivative 2 (fluostatin D) is the isobutyric ester of 1, and fluostatin E (3) can formally be considered as the ring-opening $\mathrm{HCl}$-adduct of $\mathbf{1}$, which reversibly converts into the epoxy derivative as has been observed during structure analysis. From two possibilities in relative stereochemistry only one was supported by selective NOE experiments. It is not evident that $\mathbf{3}$ is a true biosynthetic product because it was detected and isolated as a minor congener during the purification procedure.

The apparent structural relationship of fluostatins with kinamycins has been noticed earlier and a mechanism for conversion of kinamycins into fluostatin analogues has been suggested [5]. Thus, derivative $\mathbf{1}$ is the corresponding analogue of ketoanhydrokinamycin [6, 7], shown in Fig. 1. Fluostatin D (2) is the corresponding derivative to isobutyryl kinamycin FL-120B [6] which further supports biosynthetic relationships of the fluostatin and the kinamycin family.

The determination of the absolute configuration by means of NMR according to Helmchen [3] revealed $(R)$ configuration for $\mathrm{C}-1$, and, consequently $(S)$-configurations for $\mathrm{C}-2$ and $\mathrm{C}-3$, respectively. Whereas the absolute configurations of $\mathrm{C}-2$ and $\mathrm{C}-3$ are in accordance with those determined for kinamycins, C-1 of compound $\mathbf{1}$ has the opposed (S)-configuration. Application of the Helmchen method for determination of the absolute configuration was complicated because of a quaternary carbon in $\beta^{\prime}$-position (fluorenone skeleton) of the secondary alcohol. Crystals with heavy atoms e.g. bromine or with derivatives of known stereochemistry could not be obtained in order to enable independent determination of the absolute configuration of fluostatins $\mathbf{1} \sim \mathbf{3}$ by X-ray analysis. Furthermore, the Mosher method proved unsuccessful because of degradation of $\mathbf{1}$ under various reaction conditions. However, the accordance with stereochemical data on kinamycin [6] is assessed as a further proof for the correct determination of the absolute configuration. From our experimental data we suggest that the absolute configuration of fluostatin C (1) is representative also for fluostatin B. In summary, this contribution further extends the series of fluostatins analogues and to our knowledge is the first example of the assignment of configuration within this family.

\section{Experimental}

LC-MS experiments were performed on a Bruker Esquire 3000plus (Bruker-Daltonics, Bremen, Germany) coupled to an Agilent 1100 HPLC system (Agilent, Waldbronn, Germany). ESI-FT-ICR mass spectra were recorded on an APEX II FTICR mass spectrometer (4.7 T, BrukerDaltonics, Bremen, Germany). NMR experiments were recorded on an AMX600 NMR spectrometer (Bruker, Karlsruhe, Germany) equipped with a 5-mm tripleresonance probehead with $\mathrm{z}$ gradients.

A needle shaped red single crystal of compound 1, suitable for X-ray structure determination, was mounted on a glass fibre and measured on a Stoe IPDS I diffractometer, using graphite-monochromated Mo-K $\mathrm{K}_{\mathrm{a}}$ radiation. The structure was solved by direct methods with SHELXS [8] and refined by least-squares methods based on $\mathrm{F}^{2}$ using SHELX-97 [9]. The non-hydrogen atoms were refined anisotropically. Hydrogen atoms not found in the difference electron density map were included in calculated positions. The final $R_{1}$ and $w R_{2}$ values were 0.1065 and 0.1397 for all data, respectively.

Crystallographic data for the structure reported in this paper have been deposited with the Cambridge Crystallographic Data Center, CCDC, No. 294865. Copies of the data may be obtained free of charge on www.ccdc. cam.ac.uk/products/csd/request.

Preparation of phenylbutyric acid esters $\mathbf{7}$ and $\mathbf{8}$ for determination of absolute configuration (Helmchen method) [3]: To a solution of compound $\mathbf{1}(5 \mathrm{mg})$ in pyridine $(500 \mu \mathrm{l})$, DMAP $(15 \mu \mathrm{l})$, DCC $(5.3 \mathrm{mg})$ and $(R)$ or $(S)$-phenylbutyric acid $(2.4 \mu \mathrm{l})$ were added and stirred at room temperature for 2 days. Further purification of $7-(R)$ and $\mathbf{8}-(S)$ was done by preparative HPLC using RP-18 and $\mathrm{H}_{2} \mathrm{O}+0.1 \%$ TFA and ACN $+0.1 \%$ TFA.

7-(R): ${ }^{1} \mathrm{H}$ NMR $\left(600 \mathrm{MHz}, \mathrm{DMSO}-d_{6}\right): \delta 6.85(1 \mathrm{H}, \mathrm{H}-$ 1), $3.87(1 \mathrm{H}, \mathrm{H}-2), 7.31(1 \mathrm{H}, \mathrm{H}-5), 7.00(1 \mathrm{H}, \mathrm{H}-8), 7.24$ (1H, H-9), 7.06 (1H, H-10), 1.37 (3H, H-12), $3.50(1 \mathrm{H}, \mathrm{H}-$ $\left.2^{\prime}\right), 1.63 / 1.92\left(2 \mathrm{H}, \mathrm{H}-3^{\prime}\right), 0.76\left(3 \mathrm{H}, \mathrm{H}-4^{\prime}\right), 7.18(2 \mathrm{H}$, phenyl), $7.22(2 \mathrm{H}$, phenyl), $7.16(1 \mathrm{H}$, phenyl).

8-(S): ${ }^{1} \mathrm{H}$ NMR (600 MHz, DMSO- $\left.d_{6}\right): \delta 6.87(1 \mathrm{H}, \mathrm{H}-1)$, 
$3.94(1 \mathrm{H}, \mathrm{H}-2), 7.29(1 \mathrm{H}, \mathrm{H}-5), 6.95(1 \mathrm{H}, \mathrm{H}-8), 7.21(1 \mathrm{H}$, H-9), 6.99 (1H, H-10), 1.50 (3H, H-12), 3.51 (1H, H-2'), 1.63/1.91 (2H, H-3'), 0.77 (3H, H-4'), 7.16 (5H, phenyl).

Acknowledgments The work was supported by a research grant of the Emmy-Noether program (SU-239/2) of the DFG and the Schering AG, Germany. Screening, fermentation and isolation work was done within ACTAPHARM project, funded by the European Commission (QLK3-CT-2001-01783). We thank Prof. A. Karagouni, University of Athens, for providing strain Acta 1383 within the ACTAPHARM collaboration.

\section{References}

1. Baur S, Niehaus J, Karagouni AD, Katsifas EA, Chalkou K, Jones A, Ward AC, Goodfellow M, Beil W, Schneider K, Süssmuth RD, Fiedler H-P. Fluostatins C, D and E, novel members of the fluostatin family produced by Streptomyces strain Acta 1383. J Antibiot, prepared for submission

2. Fiedler H-P. Biosynthetic capacities of actinomycetes.1. Screening for secondary metabolites by HPLC and UVvisible absorbance spectral libraries. Nat Prod Lett 2:
119-128 (1993)

3. Helmchen G. New method for the determination of the absolute configuration of chiral secondary alcohols and amines. NMR spectroscopy of diastereoisomeric esters and amides of $\alpha$-phenylbutyric and hydratropic acid. Tetrahedron Lett 16: 1527-1530 (1974)

4. Akiyama T, Nakamura K, Takahashi Y, Naganawa H, Muraoka Y, Aoyagi T, Takeuchi T. Fluostatins A and B, new inhibitors of dipeptidyl peptidase III, produced by Streptomyces sp. TA-3391. II. Structure determination. J Antibiot 51: 586-588 (1998)

5. Proteau P, Li Y, Chen J, Williamson R, Gould S, Laufer R, Dmitrienko G. Isoprekinamycin is a diazobenzo[a]fluorene rather than a diazobenzo[b]fluorene. J Am Chem Soc 22: 8325-8326 (2000)

6. Young J, Ho S, Ju W, Chang L. FL-120A.apprx.D', new products related to kinamycin from Streptomyces chattanoogensis subsp. taitungensis subsp. nov. II. Isolation and structure determination. J Antibiot 47: 681-687 (1994)

7. Gould S. Biosynthesis of the kinamycins. Chem Rev 97: 2499-2509 (1997)

8. Sheldrick GM. Acta Crystallogr Sect A51 (1995) 33.

9. Sheldrick GM. SHELX-97, Universität Göttingen 1997. 